\title{
A dinâmica de produção de conhecimento: teorias e dados, pesquisador e pesquisados.*
}

\author{
Dèsirée Motta-Roth \\ Labler/UFSM
}

As maneiras de desenhar a prática de pesquisa, de construir um discurso sobre ela e de materializá-la no texto variam de acordo com as culturas locais de cada disciplina acadêmica, seus valores e crenças (Becher, 1981; Swales, 1990; Hyland, 2000). Em áreas duras como a física e a química, tradicionalmente se verificou uma tendência ao consenso (Kuhn, 1970), com fundamentos conceituais e procedimentais acordados entre os membros. A cultura coesa das áreas duras foi vista por Thomas Kuhn como sinal de ciência madura, pois evidenciava argumentos consensuais, verificados, testados, discutidos no coletivo da disciplina ao longo de séculos. As ciências humanas e sociais, por outro lado, têm se caracterizado pela recência da sua organização enquanto disciplina, pela novidade de seus argumentos e pela pouca amplitude de seu consenso (Rorty, 1991). Essa natureza heterogênea da validação do conhecimento e da caracterização do objeto de estudo é vista, neste trabalho, mais como qualidade a ser saudada do que como defeito a ser excluído. Para estudar um objeto tão complexo e rico como a linguagem humana, a Lingüística Aplicada desenha procedimentos que se socorrem em outras tantas disciplinas limítrofes, como a psicologia (na pesquisa cognitivista), a antropologia (na pesquisa etnográfica) e a sociologia (na pesquisa em análise do discurso). O surgimento de diferentes possibilidades para a prática de pesquisa vem acompanhado de discussões sobre a legitimação dos problemas e procedimentos de pesquisa. Diferentes desenhos demandam, entre outras coisas, perspectivas diversas do pesquisador sobre a linguagem e como

\footnotetext{
* A origem deste trabalho foi a comunicação apresentada no XVII Encontro Nacional da ANPOLL (Gramado, RS, 2002), na Mesa Redonda inter-subGTs: "Questōes éticas e metodológicas na pesquisa em Linguística Aplicada", do GT de Lingüística Aplicada. Agradeço o apoio do CNPq (Bolsa de Produtividade em Pesquisa no. 350389/98-5) e ao English Language Institute, Universidade de Michigan, nas pessoas de Joan Morley e John Swales.
} 
estudá-la. Este trabalho examina dois conceitos ligados a a essa questão: a perspectiva ética e a perspectiva êmica, tentando relacioná-las a diferentes modos de investigar a linguagem. Por ser de natureza complexa e rica, a linguagem demanda que acomodemos, na metodologia de pesquisa, uma 'tensão dialética' entre direções opostas. Assim, no processo de investigação, tentamos ancorar os dados no seu contexto de situação e, ao mesmo tempo, relacioná-los ao contexto mais amplo da teoria. Procuramos significação na recorrência de elementos linguiísticos e, ao mesmo tempo, buscamos explicar qualitativamente a natureza desses elementos. Desenvolvemos a habilidade de delimitar e observar um dado contexto de pesquisa e, ao mesmo tempo, tentamos neutralizar esse olhar de fora, para penetrar nesse contexto e obter um 'olhar de dentro'.

\section{Introdução}

Há algum tempo, temos visto pesquisadores na busca por explicitar como o conhecimento é produzido em diferentes áreas e em que medida essas diferentes formas do conhecimento humano constroem suas diferenças, desde exemplos já clássicos como o estudo arqueológico de Foucault (1966) na filosofia, até mais recentes na linguística aplicada como Becher (1981), Swales (1990) e Hyland (2000).

Especificamente no Brasil, a análise do texto perpassado pelo discurso de diferentes áreas nos tem apontado uma variedade de formas para se construir o objeto de estudo e a maneira de se chegar a esse conhecimento (ver, por exemplo, Coracini, 1991).

As diferentes culturas em cada disciplina acadêmica, com valores e crenças próprias, concebem diferentes maneiras de desenhar a prática de pesquisa. As áreas duras como a física e a química, tradicionalmente, tendem ao consenso (Kuhn, 1970), com fundamentos conceituais e procedimentais acordados entre os membros. Nas ciências humanas e sociais, diferentes estudos apontam que a discensão é a regra, como o trabalho de Becher $(1981 ; 1987)$, sobre o que se constitui em valor em cada campo do saber ou, mais recentemente, o texto de Marcondes Filho (1999), na conferência sobre novas epistemologias na PUC-Rio.

Por outro lado, a cultura coesa das áreas duras foi vista por Kuhn (1970) como sinal de ciência madura, pois evidenciava práticas discursivas unívocas (que ele chamou de 'generalizações simbólicas'), 
crenças ('paradigmas'), valores e soluções ('exemplares') compartilhados, na forma de argumentos consensuais, verificados, testados, discutidos no coletivo da disciplina ao longo de séculos.

As ciências humanas e sociais, por sua vez, têm se caracterizado pela recência da sua organização enquanto disciplina, pela novidade de seus argumentos e pela pouca amplitude de seu consenso. No caso específico da lingüística, a ética da discensão leva ao que Harris (1993) chamou de 'guerras internas'.

Em trabalho anterior sobre resenhas acadêmicas em três disciplinas (Motta-Roth, 1995; 1998), abordo tais diferenças entre as 'ciências' em termos de como a química, a economia e a lingüística variam no seu discurso da crítica e do elogio a novas publicações. A análise textual aponta os valores culturais de cada disciplina. Em química, a recência do livro e a uniformidade das resenhas demonstram a tendência ao consenso e a preocupação do resenhador com a disciplina. Na linguística, a preocupação do resenhador em avaliar o aporte pedagógico e a demonstrabilidade das teses do livro projetam a preocupação com o leitor, alvo da produção de conhecimento. Em economia, o autor é o alvo da criticidade frontal do resenhador em termos do rigor e da elegância do modelo matemático adotado no livro. Essas diferenças no texto e no discurso de um mesmo gênero acadêmico evidenciam diferenças no próprio conceito de 'conhecimento'. Os resultados da análise de resenhas - textos que qualificam a produção de conhecimento na forma de livro e de entrevistas - com editores de conhecidos periódicos que publicam resenhas em cada área - sugerem diferenças nos textos em relação ao que é considerado conhecimento 'legítimo e confiável' e ao grau de consenso existente em torno disso entre os membros de cada disciplina.

Embora seja tentador oferecer a imagem de que a área de estudos da linguagem é uma 'comunidade discursiva' monolítica, a dificuldade de se precisar tal construto é evidente em função do que Lemke (1995:150) define como a heterogeneidade de nossos repertórios de práticas adquiridas em nosso recorrente engajamento no discurso de diversos grupos e categorias sociais. Para Lemke, o conceito de 'comunidade' não pode ser definido por unidade, solidariedade, crenças e valores compartilhados de maneira incontroversa, mas sim, pela heterogeneidade organizada e pela articulação sistemática das diferenças individuais (p.151).

Assim, parto do princípio de que a natureza heterogênea da Lingüística Aplicada, em termos de validação do conhecimento e da 
caracterização do objeto de estudo, é antes uma qualidade a ser saudada do que um defeito a ser excluído. Se acreditarmos na premissa da discensão nas ciências humanas e sociais, então a possibilidade de se discutir variantes metodológicas ${ }^{17}$ na pesquisa em Linguística Aplicada (LA) só pode ser vista como um sinal de que a área chega a sua maturidade, na crença de que só pelo debate entre posições heterogêneas se chega ao respeito da diferença. No Brasil, a preocupação de lingüistas aplicados como Moita Lopes (1994) e Telles (2002) sobre questões de metodologia de pesquisa atestam essa maturidade pelo esforço de desenhar maneiras próprias de investigar a linguagem.

\section{Metodologia como modo de conceber o objeto de estudo}

Em qualquer área, para definir a metodologia a ser usada, é preciso antes definir nossa visão do nosso objeto de estudo e daquilo que pensamos ser cognoscível por meio de investigação sistemática. Marcondes Filho (1999:83) nos explica essa questão em termos das relações entre 'teoria' e 'técnica':

1. a realidade existe de forma determinada, totalmente independente de nosso conhecimento;

2. a realidade é a correspondência entre nosso conhecimento e a natureza do real.

A primeira, remete a um 'conhecimento contemplativo da realidade abstrata, o domínio... do estável, do imutável' - a teoria. A segunda remete a um conhecimento operacional, instrumental que tem sido a baliza da tradição moderna, desde o século XVI) - a técnica. Esta pressupõe limitações impostas pela habilidade humana de manipular a realidade, pelo material e pelos instrumentos de que dispõe para essa manipulação e compreende todos os conhecimentos aplicados, da medicina à escultura (Idem:80).

Para ele, se a tradição antiga valorizou a teoria , a tradição moderna enfatizou a técnica - a aplicabilidade das soluções que criamos a partir de nossa teoria localizada (Idem:81). A pesquisa recente sobre linguagem, texto e discurso (ver, por exemplo, Davis, (1995); Eckert, (1997); Titscher, Meyer, Wodak \& Vetter, 2000) remete a um casamento entre 'teoria' e

Não sei até que ponto elas não são também éticas, mas esse ponto deverá ser abordado em outra ocasião. 
'aplicação'. Nesses termos, o objeto de estudo da LA - a variedade de práticas sociais que a linguagem media e constrói - seria dialeticamente determinante de nosso conhecimento (e, portanto, construíriamos uma 'teoria' acerca desse objeto de estudo) e resultante de nosso conhecimento e da linguagem que o constitui (e, portanto, construíriamos uma 'técnica' que se adeque à nossa concepção desse objeto). Nessa relação dialética, o objeto determina o discurso e é, ao mesmo tempo, constituído por ele.

Como exemplo, tomo o artigo acadêmico como relato, materialização da prática de pesquisa. Considerando o poder constitutivo da linguagem sobre a ciência, ao escrever um artigo não apenas 'represento' prática de pesquisa na minha disciplina, mas, as 'produzo' (Hyland, 2000:3). Se essa idéia prevalece, cabe ao pesquisador construir uma narrativa ou um relato escrito que coloque ordem em um conjunto desordenado de dados de pesquisa (conforme Latour \& Wolgar, 1986:34) de modo que fatos científicos e relatos se construam dialeticamente (Idem:40). Nesse caso, qualquer metodologia de pesquisa é uma construção conjunta entre uma 'teoria' mais ampla que tenta dar conta de fenômenos que se inscrevem em uma dada categoria e uma 'técnica' localizada, construída sob medida, para dar conta de uma situação específica que se quer investigar.

\section{O ponto de vista do pesquisador mos estudos da linguagem}

A pesquisa sobre linguagem considera também a dicotomia 'éticoêmico', além da 'técnica-teoria'. A ciência modernista consagrou a perspectiva 'ética' como o olhar objetivo e isento do pesquisador sobre um dado grupo de dados (o corpus) ou uma população pesquisada, em cuja exterioridade ele se coloca e, enquanto participante externo ao contexto pesquisado, evita que sua subjetividade determine um viés interpretativista sobre os mesmos. Esta seria a perspectiva a adotar em uma pesquisa 'científica'.

No entanto, na segunda metade do século XX, Kuhn ([1962]1970:111) chamava nossa atenção para o fato de que, durante as revoluções científicas, velhos fenômenos são vistos sob um novo olhar e, portanto, novos fenômenos são 'descobertos' e novas maneiras de se olohar o mundo são forjadas. Somos 'equipados' pela experiência a enxergar determinados objetos e não outros (p.113), sendo assim, o 
cognoscível é determinado por nossas condições sociohistóricas. Tais debates se avolumam e chamam a atenção para a impossibilidade do pesquisador manter o distanciamento do seu objeto, uma vez que ambos são construídos mutuamente - o objeto ajuda a delimitar o ser e viceversa - e resultam das interações sociais que os envolvem. Assim, em tempos de capitalismo tardio, o que chamamos de ciência 'aposta numa reconciliação entre o domínio da natureza e o domínio dos vínculos humanos' e 'concebe o homem e a natureza ... como um devir incessante' (Kahl, 2000:16,41), em cujo processo de pesquisa, 'não podemos abstrair o fenômeno das circunstâncias restritas em que ele se dá' (idem).

Nesses termos, a linguagem, como fenômeno em um campo de conhecimento, é vista contemporaneamente não mais como sistema abstrato de regras, independente do ser e do pesquisador, mas como texto, discurso, gênero textual, que pressupõe as condições sociohistóricas que o produziram. Essa concepção de linguagem suscita uma discussão importante sobre a abordagem metodológica que possibilita seu estudo. Parece evidenciar a necessidade de abandonarmos a exclusividade da perspectiva "ética' ${ }^{19}$ do pesquisador, em favor de uma combinação com a interpretação 'êmica', interna ao sistema dos pesquisados, em que o pesquisador busca a interpretação dos participantes sobre o contexto de situação que produziu o texto (Davis, 1995: 433).

\section{Perspectiva 'ética'}

No perspectiva 'ética', situo trabalhos de M.A.K. Halliday \& Ruqaya Hasan (1989) e de Hasan (1995), cuja perspectiva adotada permite estudar a dinâmica social a partir do estudo do texto, como materialidade dessa dinâmica.

Hasan (1995:190) afirma que:

A construção de significações a partir da linguagem e a construção do contexto a partir dessas significações não são atividades dissociadas.

No início da década de 90, Fairclough (1992a: 210-11) também enfatiza que 'o texto se constitui em uma das principais fontes de evidência para embasar argumentos sobre estruturas sociais'. Dentro da

'Tso o termo 'ético' no sentido correspondente ao termo etic em inglês. 
Análise Crítica do Discurso, a análise do texto possibilitaria a reconstrução do seu contexto de produção e consumo e se constituiria em 'técnica' importante, tanto para a comunidade heterogênea dos analistas do discurso quanto para a comunidade mais ampla dos cientistas sociais.

Segundo Fairclough, para fazer Análise Crítica do Discurso (ACD), devemos nos 'engajar na pesquisa social e etnográfica por longos períodos em contextos institucionais específicos' (p. 215). A pesquisa etnográfica interpreta culturas ou grupos sociais particulares a partir do olhar de dentro, dos seus membros sobre o significado de suas práticas. Nesse ponto, salvo melhor juizo, chegamos a um impedimento metodológico para conciliar a perspectiva êmica e a ACD, pois esta parece se concentrar nos dados, ao invés de na coleta, foco característico dos estudos etnográficos. Se, de acordo com Fairclough (1992a), o objetivo da ACD é desvelar as relações de poder naturalizadas pelo discurso, e se essa ideologia opera para naturalizar visões de mundo que não são naturais, minha pergunta é: como construir uma visão 'êmica' do texto e do discurso se os sujeitos estudados nem sempre conseguem ou até desejam explicitar essa ideologia? Em outras palavras, como contar com a interpretação do sujeito para desvelar sua própria interpretação ou intenção de reforçar relações assimétricas de poder se essa interpretação pode trabalhar contra esse sujeito? Alguém generosamente revelaria isso a um pesquisador? A análise de Fairclough (1989:181) sobre o discurso de Margaret Thatcher enfatiza essa impossibilidade:

\section{[Margareth Thatcher] also rejects populist,...MT's (Margareth Thatcher) answers steer the interview away from directions which [the interviewer] seems to be trying to go in, but which would be problematic for MT in terms of her claims to solidarity with 'ordinary people'.}

Metodologicamente, a ACD poderá buscar a qualidade da análise e da interpretação dos resultados nas teorias e na descrição detalhada do observador 'daquilo que vê as pessoas observadas fazerem' (Davis, 1995:434), gerando uma descrição 'rica' em detalhes (rich description), mas para ter uma descrição 'espessa' (thick) do contexto deve contar com o 'olhar de dentro' dos participantes do contexto. Para iluminar a 
análise do texto e do discurso, uma possibilidade é o analista contar com o não-dito como elemento que constrasta e evidencia o que, de fato, é dito, mas essa discussão não é simples e necessita ser sistematizada, mas não neste artigo.

\section{Perspectiva 'êmica'}

No caso da perspectiva 'êmica' (de dentro), situo trabalhos de autores que buscam desvelar valores da cultura local por meio de entrevistas e observação detalhada junto aós membros dessas mesmas culturas. Nesse caso o analista do texto ou do discurso ou do gênero, busca a visão 'de dentro', a visão particular do participante do contexto daquela cultura que gerou o texto. Nesse segundo caso, situo estudos que buscam uma descrição 'espessa' (thick description) de como os participantes do evento se vêem, sua interpretação sobre suas próprias ações e outras informações culturais (Davis, 1995:433). Ao discutir dados de uma pesquisa sobre variação fonológica da fala de adolescentes em uma escola em Detroit, EUA, Penny Eckert (1997) usa descrições detalhadas das condições materiais do contexto e os significados compartilhados internamente pelos membros do grupo social envolvido. Ela identifica fatores como o sistema de valores da cultura escolar (a oposição entre estudantes mais e menos engajados nas atividades acadêmicas e sociais promovidas pela escola), os interesses, as ações habituais e os valores mantidos por cada grupo. Para Eckert (Idem:56), a habilidade do pesquisador depende da análise social da comunidade para identificar categorias e construir familiaridade com sua rotina diária. Ela considera que a observação e a entrevista dão acesso mais efetivo aos significados, aos valores e às interpretações do grupo sobre sua própria dinâmica social. Por se configurarem como um rompimento de papéis (o pesquisador não é membro do grupo embora esteja no grupo), esses procedimentos metodológicos demandam uma negociação cuidadosa com o contexto pesquisado, para estabelecer corresponsabilidades, confiança no anonimato. No Brasil, o trabalho desenvolvido na última década por Luiz Paulo Moita Lopes (2002) tem tido preocupação semelhante.

A área de Análise de Gêneros Textuais também tem produzido estudos que adotam uma metodologia etnográfica ao propor um mapeamento do contexto de cultura pesquisado para poder entender o 
contexto de situação de interesse para o pesquisador. $O$ trabalho recente de Swales (1998) sobre o papel de diferentes gêneros em cada disciplina acadêmica tem buscado integrar a visão interna à disciplina, conforme dada por seus membros, à interpretação externa do pesquisador. Ao realizar um estudo textográfico, Swales busca fazer sentido de cada comunidade de prática por meio da análise do discurso local. Para tanto, faz observações do contexto físico, notas de campo, entrevistas com os participantes e análise dos textos produzidos por esses participantes.

Outro exemplo é o estudo desenvolvido por Swales, Barks, Ostermann \& Simpson (2001) sobre a especificidade do uso da linguagem em um curso de Mestrado em Arquitetura na Universidade de Michigan e as percepções dos alunos nessa cultura disciplinar. Os pesquisadores relatam o processo exploratório desse contexto de cultura ao longo de quatro anos, durante os quais observaram studios, examinaram os trabalhos dos alunos e a avaliação recebida por eles, refletiram sobre os materiais que adornam as paredes dos corredores do prédio e cobriram uma vasta revisão da literatura. O objetivo era estudar o gênero 'crítica final', em que os alunos devem defender seus projetos diante de uma banca. Para tanto, gravaram sessões onde essa 'crítica final' era apresentada e realizaram entrevistas com membros da comunidade disciplinar para que estes julgassem quais os exemplares do gênero mais e menos bem sucedidos a partir de critérios internos à área.

Essa imersão no contex to de cultura local também é um dos aspectos mais acentuados na metodologia etnográfica, já que pressupõe participação do etnógrafo, aberta ou veladamente, na vida diária das pessoas por uma certa extensão de tempo, observando e ouvindo, fazendo perguntas e coletando todo e qualquer dado que lhe ajude a entender o objeto de sua pesquisa (Titscher, Meyer, Wodak \& Vetter, 2000:92).

Tanto no estudo de Eckert (1997) quanto no mais recente trabalho de Moita Lopes (2002:25-7; 85-8) sobre a construção discursiva da identidade em sala de aula, é clara a preocupação dos autores em descrever detalhadamente a situação de pesquisa - espaço físico do contexto estudado na escola, na sala de aula, a população estudada, os modos de interação e a cultura grupal dessa população:

...em uma turma de 5 a série, em aulas de língua materna, em uma escola da rede pública, no ano de 1992, na cidade do Rio de Janeiro. A escola 
está localizada no subúrbio..., uma biblioteca pequena e fechada,... banheiros pouco asseados, ...mas com um corpo docente atuante. (...)No pátio, os alunos brincam... Na hora da entrada e da saida, os pais são vistos lado a lado com pipoqueiros e vendedores de doces...Quando um professor falta, o barulho...é grande. A escola não tem inspetores... Os alunos que aparticipam da pesquisa tinham, então, entre 11 e 12 anos...A maior parte ... de origem africana. A professora era graduada em Letras...para completar seu salário, trabalhava...As slas de aula eram organizadas... Os padrões interacionais desse grupo...os professores lideram as assimetrias interacionais (Idem:25-6).

Em seguida, a metodologia de pesquisa é apresentada - a coleta dos dados, os instrumentos de pesquisa, as posições ocupadas pelas pessoas no espaço físico durante a coleta dos dados:

...um total de 32 aulas (cada aula com duração de 45 minutos)... gravações em áudio e vídeo das aulas, notas de campo e entrevistas semiestruturadas com os alunos e a professora. A professora carregava um pequeno gravador na cintura e um microfone de lapela... também dois gravadores maiores,... situados em lugares diferentes na sala... analisam os primeiros 35 minutos de uma única aula, no dia...com a finalidade de dar conta de um único evento: uma aula...focalizam os discursos de identidade em construção... (Idem: 26-7).

Uma das diferenças principais entre a pesquisa etnográfica e a Análise de Gêneros Textuais talvez esteja na ênfase: estudos etnográficos enfatizam o processo de coleta dos dados como parte integral e condicionante da análise dos mesmos, enquanto que, na Análise de Gêneros Textuais, o foco parece ser a qualidade dos dados e a verossimilhança dos exemplares em relação ao gênero cujo 
funcionamento se quer explicar. Uma questão relativa à pesquisa de cunho etnográfico é que ela se propõe a investigar os significados produzidos pelos membros do grupo na interação oral frente a frente, em tempo real, e explicar esses significados a partir das interpretações desses membros. No entanto, durante uma entrevista, por exemplo, sempre há a possibilidade de que a análise feita pelos entrevistados dos tópicos propostos pelo pesquisador tenham um viés, pela impossibilidade do sujeito e do pesquisador de se distanciarem da situação de pesquisa que envolve o monitoramento do pesquisador. A questão é: em que medida $\mathrm{o} / \mathrm{s}$ pesquisador/es conseguem mimetizar sua inserção no sítio pesquisado.

\section{Considerações finais}

Como se pode notar pelos autores citados, há aqui referência explícita a sub-áreas dos estudos da linguagem como Gramática Sistêmica, Análise Crítica do Discurso, Etnografia da Comunicação e Análise de Gêneros. O que todos parecem ter em comum é a preocupação com a linguagem como um sistema de mediação de intersubjetividade. No entanto, as maneiras de se chegar aos resultados das análises se diferenciam na ênfase dada a cada aspecto do estudo. Nisso, me parece haver um avanço, na medida em que a metodologia etnográfica considera fatores sociais e individuas, valorizando o papel da cultura que produz o texto, o sistema de valores e crenças que subjaz a ela, o significado que o contexto tem para os participante dele, a imagem que cada participante tem de si, do outro e dos significados produzidos por meio do texto (Eckert, 1997:52).

A Análise de Gêneros Textuais em contexto específicos, cada vez mais, parece incorporar esforços em duas direções: situar os dados no seu contexto de situação e relacionar esses resultados ao contexto de cultura que congrega diferentes eventos discursivos e grupos sociais. Para tanto, parece desejável se elaborar uma 'descrição espessa' do contexto, em que se considerem 'fatores teoricamente salientes, que, tanto no nível micro quanto no macrocontextual, mantêm relação sistemática com o comportamento ou eventos que se quer explicar' (Davis, 1995:434). 


\section{Referências bibliográficas}

BECHER, T. Disciplinary discourse. Studies in Higher Education. 12(3):261-74. 1987.

. Towards a definition of disciplinary cultures. Studies in Higher Education, 6 (2):109-122. 1981.

CORACINI, M. J. Um'fazer persuasivo: o discurso subjetivo da ciência. Campinas: Pontes. 1991.

DAVIS, K. Qualitative theory and methods in applied linguistics research. TESOL Quarterly, v. 29, n. 3, p. 427-53, 1995.

ECKERT, P. Why ethnography? In: Kotsinas, U.-B.; Stenstrom, A.-B., Karlsson, A.-M. (Ed.). Ungdomsprak i Norden. Stockholm: Stockholm University, 1997. p. 52-62.

FAIRCLOUGH, N. (1989). Language and power. New York: Longman. . Discourse and text: linguistic and intertextual analysis within discourse analysis. Discourse \& Society, v. 3, n. 2, p. 193-217. 1992a. Critical language awareness. New York: Longman.1992b.

HALLIDAY, M.A.K. \& R. HASAN. Language, context, and text: Aspects of language in a social-semiotic perspective. Oxford: Oxford University Press. 1989.

HARRIS, R. A. The linguistics wars. New York: Oxford University Press. 1993.

HASAN, R. The conception of context in text. In: FRIES, P.; Gregory, M. (Ed.). Discourse in society: systemic functional perspectives. Meaning and choice in language - studies for Michael Halliday. Norwood, NJ: Ablex. 1995. p. 183-83.

KAHL, M. L. F. A interpretação do sonho de Freud. Santa Maria: Editora UFSM.2000.

KUHN, T. S. The structure of scientific revolution. Chicago: The University of Chicago Press. [1962] 1970.

LEMKE, J.L. Textual politics: discourse and social dynamics. London/ Bristol, PA: Taylor \& Francis. 1995.

MARCONDES FILHO, D. Epistemologia tradicional e epistemologia contemporânea. In: OLINTO, H. K., SCHOLLHAMMER, K. E. (Org.). 
Novas epistemologias: desafios para a universidade do futuro. Rio de Janeiro: NAU: PUC, Departamento de Letras. p.79-91. 1999.

MOITA LOPES, L. P. Identidades fragmentadas. Campinas: Mercado de Letras. 2002.

Pesquisa interpretativista em Linguística Aplicada: a linguagem como condição e solução. D.E.L.T.A, v. 10, n. 2, p. 329-38. 1994.

MOTTA-ROTH, D. Discourse analysis and academic book reviews: a study of text and disciplinary cultures. In: Coll, J. F., Fortanet, I., Palmer, J. C. Posteguillo, S. (Eds.) Genre studies in English for Academic Purposes. Castellón, Espanha: Universitat Jaume I. p.29 - 48. 1998.

RORTY, R. Objectivity, relativism, and truth. Philosophical papers Volume 1. Cambridge: Cambridge University Press. 1991.

SWALES, J. M. Genre Analysis. Cambridge: CUP. 1990 Other floors, other voices: a textography of a small university building. Mahwah, NJ: Lawrence Erlbaum. 1998.

SWALES, J.M., D. BARKS, A. C. OSTERMANN \& R. C. SIMPSON . Between critique and accommodation: reflections on an EAP course for Masters of Architecture students. English for Specific Purposes, v. 20, n.4, p. 439-458, 2001.

TELLES, J. A. "É pesquisa, é? Ah, não quero, não, bem!" Sobre pesquisa acadêmica e sua relação com a prática do professor de línguas. Linguagem \& Ensino, v. 5, n. 2, p. 91-116, 2002.

TITSCHER, S., M. MEYER, R. WODAK \& E. VETTER. Methods of text and discourse analysis. London/Thousand Oaks/New Delhi: Sage. 2000. 